\title{
Adolescents' perceptions of health and well-being: Influences of urban contemporary music
}

Cindy Swartbooi, Shazly Savahl, Deborah Isobell, Gadija Khan, Cassandra Wagenaar, Fadzisai Makonyonga, Thandokazi Maseti, Laaiqah Parker and Tshinondiwa Ramaite

\begin{abstract}
The study aimed to explore adolescents' perceptions of how urban contemporary music influences health and well-being among them. Data on health and well-being effects of music consumption were gathered from a convenience sample of 16 participants ( $\mathrm{male}=50 \%$, females $=50 \%$ ) between the ages of 15 and 17 in a series of two focus group interviews. The data were analysed using thematic analysis. Findings suggest the adolescents to perceive both positive and negative influences of contemporary music on their health and well-being. Positive influences included emotional well-being and sense of social belongingness. Negative influences included promotion of risky behaviours, including substance use, misogyny, sexual behaviour and violence. The findings suggest that urban contemporary music serves as a tool of normalisation as well as a catalyst for encouraging risky behaviour in adolescence.
\end{abstract}

\section{Introduction}

Music plays an important role in the social and personal lives of adolescents (Claes \& Miranda, 2004), and is a key socialisation agent for adolescents in their identity formation in terms of ethnicity, sexuality and gender (Padilla-Walker, 2006; Cohen, 2008). At the same time, consumption by adolescents has become a matter of public-health concern for the risky behaviours it promotes (Slater, 2003), such as from images glamorising 'guns, sexual violence, and exploitation' (Gaztambide-Fernández, 2011, p. 4).

Urban contemporary music (UCM) is a term that was coined by New York-based radio disk jockey (DJ), Frankie Crocker in the 1970s (Gaztambide-Fernández, 2011), and has been linked to the propagation of a narrow set of ideas and images, particularly of gender and sexuality (Gaztambide-Fernández, 2011). Many variants of UCM exist today and are an indelible aspect of youth culture. The current study reports on what role adolescents from a historically disadvantaged, South African urban community perceived music to play in their lives. 


\section{Health promotion and undermining of music consumption}

Music consumption has been associated with energy and mood enhancing qualities and fending off boredom (Mulder et al., 2009). Adolescents experienced positive emotions when they listened to music as a backdrop for emotional ease (Getz, ChamorroPremuzic, Roy, \& Devroop, 2012). UCM has been found to carry health and well-being undermining messages, including misogyny, which is associated with (a) derogatory naming and shaming of women, (b) sexual objectification of women, (c) distrust of women, (d) legitimation of violence against women, and (e) celebration of prostitution and pimping. It is also associated with the uptake of harmful smoking and drinking by adolescents (Roberts, Christenson, Henriksen \& Bandy, 2002; Primack, Gold, Schwartz \& Dalton, 2008; Mulder et al., 2009). For instance, results from a content analysis undertaken by Roberts et al. (2002) indicate that $45 \%$ of the music videos viewed by adolescents portrayed (licit or illicit) substances, while $33 \%$ of the videos made verbal references to it. Similarly, Primack et al. (2008) found that $33 \%$ of the songs subjected to content analysis depicted substance use. An affinity with particular music genres is important for friendship selection during adolescence (see Bakagiannis \& Tarrant 2006). Floyd, Alexandre, Hedden, Lawson and Latimer, (2010) found the sale of licit and illicit substances to be commonplace between adolescents and their peers, while all participants in a South African qualitative study conducted in the Cape Flats region reported enhancement motivation, using substances for pleasure (Patrick et al., 2010).

The display of sexual content in the media has been linked to risky sexual behaviour among adolescents and youths (Andsager \& Roe 2003; Brown, Kenneavy \& L’Engle, 2006). In their qualitative evaluation of two decades of literature on music videos, Andsager and Roe (2003) found that messages relating to sex and gender contained stereotypes, sexual innuendo and suggestiveness, and provocative clothing. Brown et al. (2006) found that adolescent's exposure to music led to higher levels of risky sexual behaviour, leading them to disregard sex education and act carelessly. Similarly, Martino et al. (2006) found that youth who listened to sexual lyrics that degrade women were more likely to initiate sex at an early age. In South Africa, a survey on sexual activity of adolescents indicated that $42 \%$ of the participants had sex at 15 years old or younger. Participants attributed this early sexual debut to frequent exposure to sexually overt content and images through the media, in particular popular music (Kelly \& Ntlabati, 2002).

Smith and Boyson (2002) found that $15 \%$ of the music videos they sampled exhibited violent and aggressive content. Adolescents exposed to this content were found to be more likely to condone the use of violence as a means of solving social problems. Kubrin (2005) posits that certain street codes with which adolescents identify (e.g. willingness to use violence or fighting, objectification of women, violent retaliation, material wealth, nihilism and respect), are present in rap music lyrics. Furthermore, the most salient functions served by violence in rap lyrics were exerting social control, and establishing social identity and reputation. 


\section{Goal of the study}

This study sought to explore South African adolescents' perceptions of urban contemporary music on their health and well-being. The aim of the study was to explore adolescents' perceptions of the role of urban contemporary music on risky behaviour. The following objectives guided the study: to determine adolescents' perceptions of the role of urban contemporary music on violence; to determine adolescents' perceptions of the role of urban contemporary music on sexual behaviour; to determine adolescents' perceptions of the role of urban contemporary music on substance use.

\section{Method}

\section{Research design}

The study employed qualitative inquiry to explore adolescents' perceptions of urban contemporary music on their health and well-being. Qualitative research seeks to understand and interpret phenomena from an individual's perspective, affording researchers an in- depth understanding (Ahmadi, Anoosheh, Vaismoradi \& Safdari, 2009). Accordingly, it aligned well with the aims and objectives of the current study which sought to provide an in-depth account of adolescents' perceptions of the influence of urban contemporary music on risky behaviour.

\section{Participants and setting}

This research project formed part of a larger collaborative research and intervention project between the school, community and university at which the researchers are based. Participants were a purposive sample of 16 adolescents (males $=50 \%$; females $=50 \%$ ), who were Grade 10 learners from a high school in an impoverished Cape Flats community in Cape Town, South Africa. The Cape Flats district is a large housing project in Cape Town, built during apartheid for the marginalised and disenfranchised 'coloured'1 communities (Loots, 2005). These communities are characterised by high levels of poverty, social disorganisation, unemployment, violence, school truancy, and substance abuse (Standing, 2003). In addition to engaging in substance abuse and violence, adolescents in these communities rely on music to escape their harsh social realities (Stanley, 2009) and to create a sense of group identity. Moreover, it is commonplace for South African adolescents to identify with American music culture. Area of residence, grade, and a willingness to participate therefore served as inclusion criteria.

\section{Data collection}

Data on adolescents' perceptions of urban contemporary music on their health and wellbeing were collected by means of focus group interviews. We hosted two mixed- gender focus group discussions with eight participants each. The focus group discussions were conducted in the school setting, guided by a semi-structured interview schedule. The interview schedule consisted of six core questions, in addition to a number of probes designed to elicit discussion. Each group interview was guided by two facilitators, were conducted concurrently in separate venues, and lasted approximately 80 minutes. Discussions were audio recorded and later transcribed verbatim by the core group of 
researchers with the permission of the participants. The transcribed texts were then verified by other members of the research team.

\section{Ethics and procedure}

Ethics clearance was obtained from the Senate Research Ethics Committee of the University of the Western Cape. Permission to gain access to the school was obtained from Western Cape Education Department. Furthermore, permission from the school principal was sought in order to conduct the study. The rationale, purpose of the study, as well as voluntary participation in the study was discussed with the learners. In accordance with the South African Constitution that views adolescents as minors, informed consent was obtained from parents or guardians, as well as the adolescents, prior to participation in the study. The focus groups commenced once consent was obtained from both the participants and their parents. Participants were not compelled to respond to any questions that they were uncomfortable with and were informed of their right to withdraw from the study. Debriefing and counselling services were made available to participants.

\section{Data analysis}

Data were analysed using the six steps of thematic analysis outlined by Braun and Clarke (2006), namely data familiarisation, generation of initial coding, searching for themes based on initial coding, review of themes, theme definition, and report writing. The formal analysis commenced after the researchers were familiar with the data (Braun \& Clarke, 2006) and had identified ideas or codes in the data. Once the initial codes were generated the researchers searched for themes by categorising codes into meaningful groups. These tentative themes were then examined and refined for the report writing.

\section{Discussion of findings}

From the thematic analysis, themes emerged to suggest that the adolescents perceived consumption of UCM to have both positive and negative influences on their health and wellbeing. We consider the specific ways in which the adolescents perceived influences of UCM on health and well-being below.

\section{Thematic category 1: Positive influences}

The participants perceived UCM to enhance their mood. The following excerpts are illustrative:

Male participant: 'Like me for instance and I feel stressed or worried about something I listen to music'

Female participant: 'Like if you are sad or depressed you like listen to depressing music so something like that'

The extracts point to music being used as a coping mechanism, especially to enhance mood. While this concurs with earlier research (Schwartz \& Fouts, 2003) that music is used to satisfy emotional needs, the participants are further suggesting that one's mood also determines one's music preference. 


\section{Significance of music}

Participants also perceived music important to their social and personal lives as demonstrated by the following extract:

Male participant: 'Music is life'

Female participant: 'I think music is really important' Male participant: 'It plays a big role in my life' Male participant: 'Never like influences in a good way'

Male participant: 'It's actually a bad influence to all of us here'

Male participant: 'It's not bad, really it's not bad'

These findings are consistent with those from previous studies (Smith \& Boyson, 2002; Slater, 2003; Keyes, 2004).

\section{Thematic category 2: Negative influences}

Participants perceived UCM as encouraging self-harm in the form of self-mutilation ('I've heard of somebody that cut themselves. They do that, cause that's what they see. That's what they told'), and name calling of women. A female participant expressed how she felt about these messages:

Female participant: 'I like Little Wayne but...like sometimes he says bad things about women...I listen to the song of Little Wayne and it says and how girls are sluts'

Male participant: 'It shows that the man should be the man in the house and the women shouldn't tell the man what to do...And they get beat up sometimes'

Female participant: '...most of the time when they saying a girl is beautiful it's when she is thin she's like wearing short skirts, short dresses, and she has long hair...You know it's like they saying that person is beautiful now'

Female participants were also concerned about the manner in which they would be perceived, as expressed below.

Female participant: '...we can't like wear anything and then people like say yoh I like your bum, like, so its look like at the other girl in the music video, like that'

Female participants expressed a concern about the use of models in music videos as they believed that it influences their perceptions of the ideal body image and body satisfaction. The presence of these messages, as identified by the participants, is consistent with studies that have found sexist and misogynist content in music (Connell \& Messerschmidt, 2005; Conrad, Dixon \& Zhang, 2009; Gourdine \& Lemmons, 2011), suggesting that certain music encourages violence, and disrespect toward women (Kubrin, 2005).

Researchers have identified these messages to be widespread in the media, and have identified the potentially detrimental effects on adolescent body satisfaction (Gordon, 2008). 


\section{Modelling of substance-use behaviours}

The adolescents perceived UCM to model substance-use behaviours as a way of life. The following excerpts are illustrative:

Female participant: 'Like they smoke weed and all that; and it just seems so cool. And I also wanna smoke weed. Because they smoke weed...kids like four or five look up to him, and they are seeing him and they think like "oh smoking kids is ok let's go do it"

Male participant: 'cos a lot children now drink cos Lil Wayne drink and they smoke cos he do it, Wiz Khalifa them and Snoop Dogg and they all do it so they think they should also do it cos they look up to him. They think they now that's their role models'

Female participant: 'If you wanna get caught up with drugs, it's your own thing. It's your own choice, you can't blame anyone else'

Female participant: 'The drug merchants like, also sell drugs to get like big things you see like they have big houses, they have the cars, they have the clothes they have everything but they didn't like work hard to get there they hustle...they like hustle like Lil Wayne...he also has his own hustle because how much times wasn't he in jail for like drug smuggling or whatever gun on him and like people are seeing that and they thinking that by them also starting a hustle they can also have things...'

Young people believed that listening to UCM led them to mimic the substance use that was exhibited in music videos. However, other participants differed in opinion, identifying free will as the most salient determinant of such behaviours. Portrayals of substance use in music videos have been identified as being pervasive (Roberts et al., 2002; Primack et al., 2008), displayed in the assertion that 'music videos not only sell songs, they also sell a way of life' (Escobedo, 2009, p. 1).

\section{Promotion of risky sexual behaviour}

The participants perceived UCM to glamourise sex, and to encourage early sexual debut. It was also seen to encourage engaging in unprotected sex and teenage pregnancy. This is evident in the excerpt below.

Male participant: 'this guy in young money, Lil' Twist, he is our age he's still like 16, still young, so that's when he got signed to the young money image so they were laughing at him, he's still a virgin'

The participants made reference to a documentary of the hip-hop artist, Lil Wayne, where he claimed to have lost his virginity at the age of nine. In this documentary, a young artist was ridiculed by older artists for being a virgin. Several authors have also found that music has been linked to early sexual debut (Kelly \& Ntlabati, 2002; Martino et al., 2006). 
Another participant reported that there was a concern for the way music videos influenced the way in which young girls in their community perceived a 'glamorous life'. They believed that many young females become involved with gangsters in the hope of a better life and to escape from their social circumstances. This finding corresponds with the study conducted by Brown et al., (2006), which found that music normalises risky sex and engaging with multiple partners as this is believed to exude social status.

\section{Promotion of violence}

Two pertinent issues were identified, namely physical and non-physical violence. The participants identified two forms of physical violence, namely gang violence, and crime.

The following extracts suggest that messages in music promote gangsterism as desirable. Female participant: 'But they like trying to say that having a gun and being a gangster is okay'

Male participant: 'Most of the gangsters, they come with these huge guns, and say I got a, uhm, they got guns in their cars, they'll shoot you dead, and all of this stuff'

Male participant: 'The same with 2pac [name of a popular hip-hop artist] when he says in that one song, 10 shots couldn't drop me, I took it and smiled. They shot him like 10 times and he didn't feel anything'

Male participant: 'I wouldn't say there's a lot of gangs at school, but there is like people from outside that influence school children...to join the gang, see. So they all get these images from music'

Male participant: 'But they like trying to say that having a gun and being a gangster is okay'

The 'gangster lifestyle' is normalised by the frequent portrayal of guns and violent acts in music videos. Participants relayed stories of lyrics alluding to artists adopting the 'gangster lifestyle'. These lyrics portrayed artists in music videos as being invincible, even surviving violence, and being shot. The literature suggests that rap music tends to glamourise gang culture in order to develop a reputation which separates listeners of this music from others (Kurbin, 2005).

Non-physical violence encompasses verbal violence, which includes foul language and gangster narratives. This is evidenced in the following extracts:

Male participant: 'Most artists use foul language in music'

Female participant: 'Yes...like the swearing is just too much, it's now like a person can't just say even one sentence without swearing, you must swear. It's bad'

Participants expressed how some music artists use foul language in their music. Cursing is understood as a normal form of expression, and this is evident in the lyrics that adolescents 
are exposed to daily. A similar point was raised by Malek (2008), who found foul language to be prevalent in adolescents' daily behaviour. Malek (2008) contends that exposure to violent language in music affects how people behave.

Abrams (2000) contends that rap music depicts violence, and the urban ghetto life in America which in turn normalises gang culture, and street wars.

\section{Hate speech: Homophobia and racism}

Participants reported that music contained homophobic messages that encourage violence toward homosexual people.

Male participant: 'Most rappers, like most hip-hop rappers all of them, they against gay people. They sing like we must kill gay people, that is true'

Participants perceived that UCM also promotes racist hate speech:

Female participant: '...You can see like if there's a black video they'll say something bad about whites, or if like there's a white video they'll say something bad about black...So it does make people racist'

Male participant: '...and those rappers are racists... Lil Wayne...Like on his music videos and songs, he says it like "fuck white people"

Similar to this observation, Muñoz-Laboy, Weinstein and Parker (2007) identify homophobia, sexism and violence as important traits that are mostly associated with hip-hop music.

\section{Limitations of the study}

As the participants focused largely on the impact of American music, it may be useful to explore their perceptions of the influence of South African music on various behaviours. Researchers should consider conducting studies which examine the impact of urban contemporary music on adolescent risk behaviour in other socio-economic conditions as this may have a mediating effect on the influence of music.

\section{Conclusion}

Adolescents identified both positive and negative influences of UCM on health and wellbeing. They engaged with urban contemporary music for different reasons, ranging from enjoying the beat of the music to finding solace in times of depression, boredom, or sadness. The importance of music was emphasised as forming an integral part of their daily existence. The participants held mixed perceptions with regard to the role of music. Some participants described music as being a bad influence, while others did not. This emphasises the importance of taking into account individual differences and situational contexts when investigating adolescents' perceptions of substance use, risky sexual behaviour, and violence.

Adolescents' perceptions of urban contemporary music's influence on risky sexual behaviour pointed to the and teenage pregnancy. Adolescents also perceived music as being 
misogynist and promoting certain body images and ideals. With regard to violence, urban contemporary music was identified as being a contributing factor to both physical and nonphysical violence, serving as both a tool of normalisation as well as a catalyst for encouraging deviant behaviour (physical and verbal) and acts of violence.

\section{Endnotes}

1 'Coloured' was a derogatory term used by the apartheid state to refer to a mixed-race group having Khoisan ancestry. This definition was used for descriptive purposes in the current study. 


\section{References}

Abrams, N. (2000). Gangsta Rap. In T. Pendergast \& S. Pendergast (eds), St James Encyclopedia of popular culture, (p. 198). Farmington Hills: Thomson-Gale. Ahmadi, F., Anoosheh, M., Vaismoradi, M., \& Safdari,

M. T. (2009). The experience of puberty in adolescent boys: An Iranian perspective. International Nursing Review, 56(2), 257-263. http://dx.doi. org/10.1111/j.1466-7657.2008.00670.x.

Andsager, J., \& Roe, K. (2003). 'What's your definition of dirty, baby?': Sex in music video. Sexuality \& Culture, 7(3), 79-97. http://dx.doi.org/10.1007/s12119-003-1004-8.

Bakagiannis, S., \& Tarrant, M. (2006). Can music bring people together? Effects of shared musical preference on intergroup bias in adolescence. Scandinavian Journal of Psychology, 47(2), 129-136. http://dx.doi. org/10.1111/j.14679450.2006.00500.x.

Braun, V., \& Clarke, V. (2006). Using thematic analysis in psychology. Qualitative Research in Psychology, 3(2), 77-101. http://dx.doi.org/10.1191/1478088706qpo630a.

Brown, J. A., Kenneavy, K., \& L' Engle, K. L. (2006). The mass media are an important context for adolescents' sexual behaviour. The Journal of Adolescent Health, 38(3), 186-192. http://dx.doi.org/10.1016/j.jadohealth.2005.03.020.

Claes, M., \& Miranda, D. (2004). Rap music genres and deviant behaviours in FrenchCanadian adolescents. Journal of Youth and Adolescence, 33(2), 113-122. http://dx.doi.org/10.1023/B:JOYO.0000013423.34021.45.

Cohen, D. (2008). The role of rap/hip-hop music in the meaning and maintenance of identity in South African youth. (Unpublished master's dissertation). University of the Witwatersrand, Johannesburg.

Connell, R. W., \& Messerschmidt, J. (2005). Hegemonic masculinity: Rethinking the $\begin{array}{llll}\text { concept. } & \text { Gender } \quad \text { \& } & \text { Society, } & \text { 19(6), }\end{array}$ http://dx.doi.org/10.1177/0891243205278639.

Conrad, K., Dixon, T., \& Zhang, Y. (2009). Controversial rap themes, gender portrayals and skin tone distortion: A content analysis of rap music videos. Journal of Broadcasting \& Electronic Media, 53(1), 134-156. http://dx.doi. org/10.1080/08838150802643795.

Escobedo, M. M. (2009). Images of aggression and substance abuse in music videos: A content analysis. (Unpublished master's dissertation). San Jose State University. Paper 3654 .

Floyd, L. J., Alexandre, P. K., Hedden, S. L., Lawson, A. L., \& Latimer, W. W. (2010). Adolescent drug dealing and race/ ethnicity: A population-based study of the differential impact of substance use on involvement in drug trade. American Journal of Drug \& Alcohol Abuse, 36(2), 87-91.

Gaztambide-Fernández, R. A. (2011). Musicking in the city: Reconceptualizing urban music education as cultural practice. Action, Criticism, and Theory for Music Education, 1O(1): 15-46. http://act.maydaygroup.org/articles/Gaztambide- Fernández 10_1.pdf. 
Getz, L. M., Chamorro-Premuzic, T., Roy, M. M., \& Devroop, K. (2012). The relationship between affect, uses of music, and music preferences in a sample of South African adolescents. Psychology of Music, 4O, 164-178. http://dx.doi. org/10.1177/0305735610381818.

Gordon, M. K. (2008). Media contributions to African American girls' focus on beauty and appearance: Exploring the consequences of sexual objectification. Psychology of Women Quarterly, 32, 245-256.

Gourdine, R. M., \& Lemmons, B. P. (2011). Perceptions of misogyny in hip hop and rap: What do the youths think? Journal of Human Behavior in the Social Environment, 21(1), 57-72. http://dx.doi.org/10.1080/10911359.2011.533576.

Kelly, K., \& Ntlabati, P. (2002). Early adolescent sex in South Africa: HIV intervention challenges, social dynamics. Journal of African Studies, 28(1), 42-63.

Keyes, C. L. (2004). Rap music and street consciousness. Illinois: University of Illinois Press.

Kubrin, C. E. (2005). Gangsta, thugs, and hustlas: Identity and the code of the street in rap music. Social Problems, 52(3), 360-378. http://dx.doi.org/10.1525/sp.2005.52.3.360.

Loots, C. (2005).Violence in South Africa Profile. The Human Rights Institute of South Africa. Johannesburg: South Africa. Malek, A. S. (2008). Violence in language: Is rap music causing violence in America? In Violence, Realities and Concerns,(pp. 107115). Beirut: Notre Dame University Press.

Martino, S. C., Collins, R. L., Elliott, M. N., Strachman, A., Kanouse, D. E., \& Berry, S. H. (2006). Exposure to degrading versus non-degrading music lyrics and sexual behaviour among youth. Pediatrics, 118(2), 430-441. http:// dx.doi.org/10.1542/peds.2006-0131.

Mulder, J., TerBogt, T. F. M. Raaijmakers, Q. A. W., Gabhainn, S. N., Monshouwer, K., \& Vollebergh, W. A. M. (2009). Is it the music? Peer substance use as a mediator of the link between music preferences and adolescent substance use. Journal of Adolescence, 33(3): 387-94.

Muñoz-Laboy, M., Weinstein, H., \& Parker, R. (2007).The hip-hop club scene: Gender, grinding and sex. Culture. Sexual Health, 9(6), 615-628. http://dx.doi. org/10.1080/13691050701528590.

Patrick, M. E., Palen, L-A., Caldwell, L., Gleeson, S., Smith, E., \& Wegner, L. (2010). A qualitative assessment of South African adolescents' motivations for and against substance use and sexual behaviour. Journal of Research on Adolescence, 2O(2), 456-481. http://dx.doi. org/10.1111/j.1532-7795.2010.00649.x.

Primack, B. A., Gold, M. A., Schwarz, E. B., \& Dalton, M. A. (2008). Degrading and nondegrading sex in popular music: A content analysis. Public Health Reports, 123, 593600.

Roberts, D. F., Christenson, P. G., Henriksen, L., \& Bandy, E. (2002). Substance use in popular music videos. United States: Office of National Drug Control. http://dx.doi.org/10.1037/ e375462004-001.

Schwartz, K. D., \& Fouts, G. T. (2003). Music preferences, personality style, and developmental issues of adolescents. Journal of Youth and Adolescence, 32(3), 205213. http:// dx.doi.org/10.1023/A:1022547520656. 
Slater, M. D. (2003). Alienation, aggression, and sensation seeking as predictors of adolescent use of violent film, computer, and website content. Journal of Communication, 53(1), 105-121. http://dx.doi.org/10.1111/j.1460-2466.2003. tbo3008.x.

Smith, S. L., \& Boyson, A. R. (2002). Violence in music videos: Examining the prevalence and context of physical aggression. Journal of Communication, 52(1), 6183. http:// dx.doi.org/10.1111/j.1460-2466.2002.tb02533.x.

Standing, A. (2003). The social contradictions of organised crime on the Cape Flats. Pretoria: Institute for Security Studies, Paper 74.

Stanley, M. (2009). Media \& Internet: How teenagers consume media. Retrieved from http://media.ft.com/cms/c3852b2e-6f9a-11de-bfc5-00144feabdco.pdf. 